\title{
Fluxo tectônico subparalelo ao Cinturão Ribeira no sul do Espírito Santo: análise das estruturas na seção Marechal Floriano-Ibatiba
}

\author{
Tiago da Rocha Karniol ${ }^{1}$ \& Rômulo Machado ${ }^{2}$
}

\begin{abstract}
Resumo Os dados estruturais obtidos ao longo da seção Marechal Floriano - Ibatiba, região sul do Estado do Espírito Santo, foram classificados em quatro domínios estruturais. O domíno I, caracterizado por gnaisses aluminosos, apresenta uma foliação NNE com mergulhos médios a baixos para ESE que é afetada por dobras abertas e contém uma lineação de estiramento subhorizontal com caimento para NNE. Os domínios II, III e IV constituem-se de uma associação de rochas plutônicas, foliadas, com mergulhos em geral de alto ângulo, associadas com estruturas em leque e zonas de cisalhamento com lineação de estiramento com caimento de baixo a médio ângulo para NNE, paralela aos eixos das dobras. Na seção investigada, os indicadores cinemáticos (pares de foliações S-C e porfiroclastos assimétricos) mostram movimentação de topo para SSW e sugerem a existência de um fluxo transpressivo nesta direção, de forma análoga ao que tem sido caraterizado no Vale do Rio Doce e na porção ocidental do Estado do Rio de Janeiro.
\end{abstract}

Palavras-chave: transpressão, fluxo tectônico paralelo ao orógeno, Cinturão Ribeira, zona de cisalhamento de Guaçuí.

\begin{abstract}
Orogen-subparallel tectonic flow on Ribeira Belt in the southern region of Espirito Santo: structural analyses on Marechal Floriano - Ibatiba section. Structural data obtained on the Marechal Floriano - Ibatiba section on southern State of Espírito Santo were aggrupated in four main structural domains: domain I consists aluminous gneisses and presents NNE-trending, moderately-to-steeply ESE-dipping foliations with subhorizontal NNE lineations and open folded pattern of planar structures. The domains II, III and IV consist of plutonic foliated rocks, commonly with steeply-dipping foliations where fan-like structures were described. In these domains, shear zones contain shallow-to-moderate NNE-plunging lineations, parallel to fold axis. Shear sense indicators (S-C foliations and assimetric porfiroclasts) are consistent with top-to-SSW tectonics in all domains, suggesting the importance of a transpressive regime on the same direction, what has already been described in the regions of the Rio Doce Valley and southern Rio de Janeiro.
\end{abstract}

Keywords: transpression, orogen-parallel tectonic flow, Ribeira Belt, Guaçuí shear zone.

INTRODUÇÃo A região sul do Espírito Santo é considerada como parte de um orógeno de idade brasiliana que se estende ao longo da costa atlântica da plataforma sulamericana, conhecido como Cinturão Ribeira (Hasui et al. 1975). O caráter transpressivo da deformação nesta região é reconhecido por vários autores e é reforçado por um arranjo estrutural que reflete uma articulação cinemática com movimentações direcional e compressiva nas principais zonas de cisalhamento (Dayan \& Keller 1989, Machado \& Endo 1993 a e b, Trompette et al. 1993, Cunningham et al. 1998, Ebert e Hasui 1998, Egydio-Silva 1996, Egydio-Silva et al. 2002, Dehler 2002, entre outros).

Desde a sua definição original (Harland 1971, Sanderson \& Marchini 1984), que os termos transpressão e transtração são relacionados à convergência e divergência oblíqua de placas tectônicas, em regimes que envolvem a combinação de cisalhamento puro e cisalhamento simples sem variação de volume. Esse conceito tem se expandido com base em modelos que consideram que o material é impedido de se deslocar em qualquer direção na zona de cisalhamento, sendo forçado a extrudir verticalmente. Ou ainda situações em que o material pode se deslocar longitudinal e verticalmente, para baixo e para cima, ou em todas as direções, tanto na vertical quanto na horizontal, dando lugar a transpressão não-confinada (Sanderson \& Marchini 1984, Tikoff \& Teyssier 1994, James \& Watkinson 1994, Robin \& Cruden 1994, Jones et al. 1997).

Recentemente, alguns autores têm mostrado a importância de movimentos oblíquos e paralelos em segmentos da Província Mantiqueira Central (Dehler \& Machado 2002, Egydio-Silva et al. 2002, Karniol \& Machado 2004, Peres et al. 2004, Dehler et al. 2006). Esses processos, em alguns locais, podem se associar à estruturas extensionais com movimentação de topo para ESE (Endo 1997, Nalini Jr. 1997, Dehler et al. 2000, Dehler 2002, Dehler \& Machado 2002, Karniol \& Machado 2004, Dehler et al. 2006 e 2007, Marshak et al. 2006, Karniol et al. 2007), situações reportadas também na literatura internacional (Jarrard 1986, Ratschbacher et al. 1991, Bird 1991, Chauvet \& Séranne 
1994, Lyberis \& Mamby 1999, Avigad et al. 2001, Harz et al. 2001, Seyferth \& Henk 2004).

Em termos estruturais, a área definida neste artigo ainda foi pouco estudada, principalmente se consideradas as técnicas atuais de análise cinemática, embora seja uma região contemplada por projetos de mapeamento geológico em escalas 1:250.000 (Projeto Jequitinhonha) e 1:100.000 (PLGB - Projeto de Levantamento Geológico do Brasil, Folhas Domingos Martins e Afonso Cláudio), realizados pela CPRM - Serviço Geológico do Brasil (Fontes et al. 1978, Féboli 1993, Signorelli 1993) e por trabalhos sobre petrologia, geoquímica e geocronologia em uma série de suítes intrusivas e sequências metamórficas, conduzidos principalmente por pesquisadores alemães na década de 80 (ver sínteses em Söllner et al. 1991 e 2000).
CONTEXTO TECTÔNICO REGIONAL O lineamento de Além-Paraíba (Almeida et al. 1975, Campanha 1981, Egydio-Silva 1996) ou zona de cisalhamento do Rio Paraíba do Sul (Dayan \& Keller 1989) é uma importante feição estrutural no Rio de Janeiro e faz parte da Província Mantiqueira Central (Hasui \& Oliveira 1984). Localiza-se a sul-sudeste do Cráton do São Francisco e corresponde a uma das estruturas précambrianas mais expressivas do sudeste brasileiro, sendo responsável pelo controle do curso do Rio Paraíba do Sul em toda a sua extensão no Rio de Janeiro. Seu traçado retilíneo é realçado em imagens de satélite ou de aerogeofísica, porém, próximo à divisa do Rio de Janeiro com o Espírito Santo - altura do paralelo $21^{\circ} 30^{\prime}$ Sul, este lineamento mostra uma mudança de direção de NE para NNE ao se conectar com a zona de cisalhamento de Guaçuí (Fig. 1).

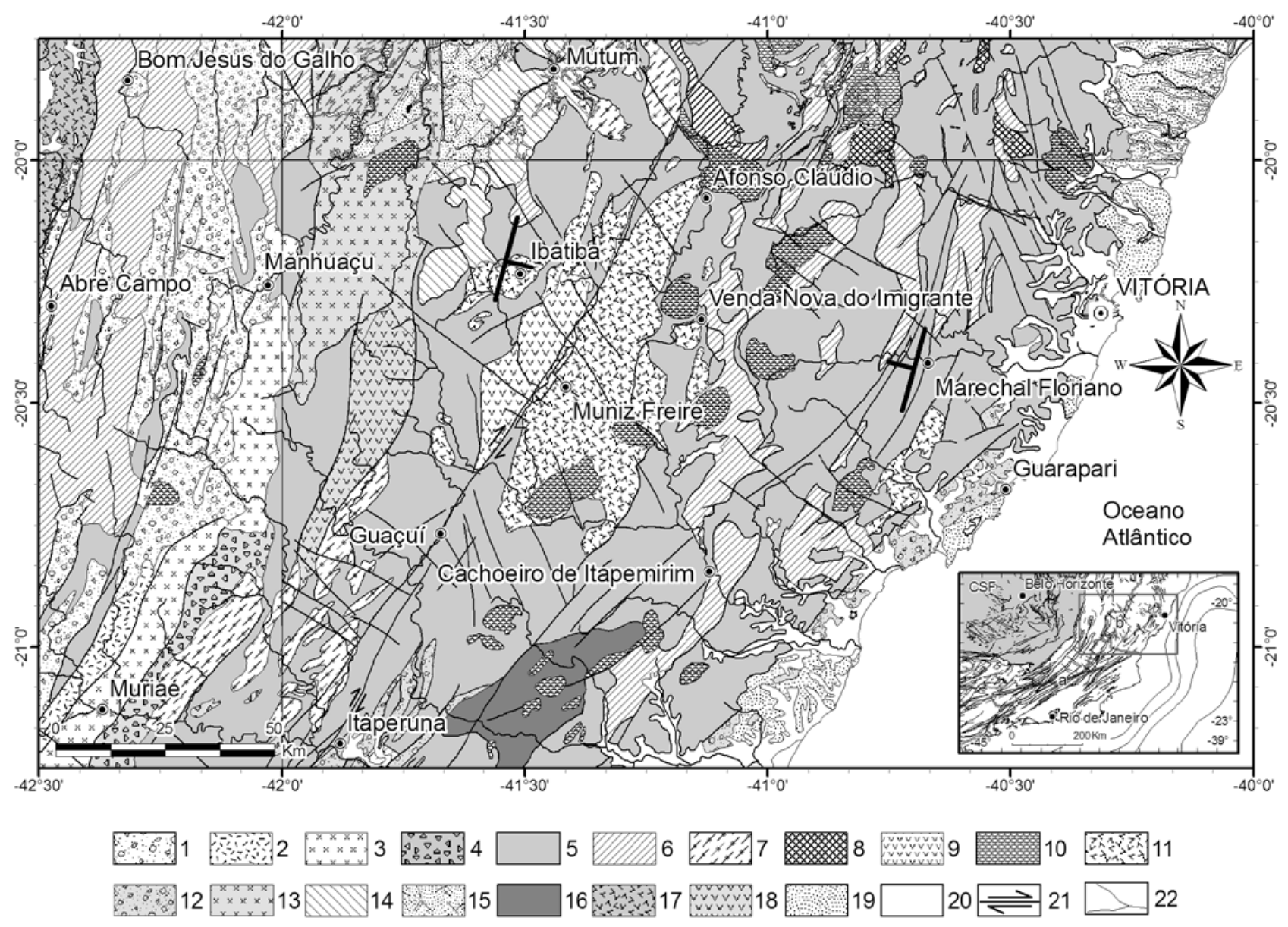

Figura 1 - Mapa geológico da área com localização do perfil entre Marechal Floriano e Ibatiba (ES) (ver figura 2). Legenda das unidades: 1- Complexo Juiz de Fora; 2- Suite Quirino; 3-Suite Muriaé; 4- Suite Charnockítica Leopoldina; 5- Complexo Paraíba do Sul; 6- Tonalitos e granitos tipo-I; 7- Granitos Eugenópolis, Varre-Sai, Suite Natividade; 8- Granito Colatina; 9- Charnockitos indivisos; 10- Maçicos intrusivos tardi a pós-colisionais; 11Batólito Muniz Freire; 12- Suite Bela Joana; 13-Complexo Pocrane; 14- Suite Galiléia; 15- Formação Palmital do Sul; 16- Suite Angelim; 17- Complexo Piedade; 18-Suíte Caparaó; 19- Grupo Barreiras; 20- Depósitos quaternários; 21-Zonas de cisalhamento; 22- Rios. No detalhe, abaixo à direita, localização da área e articulação regional entre as principais estruturas e o Cráton do São Francisco (CSF, em cinza), destacando-se o Lineamento de Além Paraíba (a) e a Zona de Cisalhamento Guaçuí (b). Fonte: CPRM - Serviço Geológico do Brasil - Mapa Geológico do Brasil ao Milionésimo (folhas SE23/SE24/SF23/SF24). 
Na porção ocidental do Rio de Janeiro o lineamento de Além-Paraíba se articula com várias zonas de cisalhamento de direção geral NNE, a principal delas denominada de Guaçuí (Chrispim \& Tupinambá 1989, Reis et al. 1982, Signorelli 1993), que se estende para o Espírito Santo e é responsável pela estruturação da parte oeste da seção estudada. Em termos estruturais, esta região do Rio de Janeiro tem sido interpretada como uma divergência estrutural simples ou em leque (Machado 1984, Dehler et al. 2006), uma megassinforma (Heilbron et al. 1991) ou ainda uma megaestrutura em flor positiva do Vale do Rio Paraíba do Sul (Machado \& Endo 1993 a).

As zonas de cisalhamento da região possuem geometria anastomosada e movimentação regional destral, evidenciada por suas características geométricas e cinemáticas (Dayan \& Keller 1989, Campanha 1981, Cunningham et al. 1998, Dehler 2002, Egydio-Silva et al. 2002, Dehler et al. 2006, Karniol et al. 2008).

As rochas do embasamento do Cinturão Ribeira/Araçuaí - complexos Mantiqueira e Juiz de Fora - são caracterizadas principalmente por ortognaisses migmatizados, de composição granodiorítica a tonalítica, subordinadamente granítica, com metamorfismo em grau alto, alcançando em vários locais fácies granulítica. Datações U-Pb de alta precisão em zircão (SHRIMP) obtidas em ortognaisses deste embasamento mostram na região do Espírito Santo e Minas Gerais idades paleoproterozóicas para estes complexos: entre 2134 e 2084 Ma, para o Complexo Mantiqueira, e entre 2195 e 2084 Ma, para o Complexo Juiz de Fora (Noce et al. 2007), intervalos compatíveis com idades obtidas por outros autores (Silva et al. 2002). Amostras do Complexo Mantiqueira possuem zircões com idades de herança arqueanas, enquanto os zircões do Complexo Juiz de Fora não apresentam idades de herança, sugerindo que este último teve uma evolução tectônica em ambiente de Arco Magmático Oceânico (Noce et al. 2007), enquanto o primeiro teria evoluído também em ambiente de arco magmático, porém ao longo de uma margem arqueana do Paleocontinente do São Francisco (Teixeira et al. 2000, Noce et al. 2007).

Os dados isotópicos disponíveis sugerem, de modo geral, um retrabalhamento crustal durante o $\mathrm{Ci}$ clo Brasiliano, envolvendo rochas transamazônicas (Cordani 1973, Machado et al. 1996, Söllner et al. 1991 e 2000, Silva et al. 2005, Heilbron et al. 2004).

MATERIAIS E MÉTODOS Os trabalhos de campo envolveram a descrição e análse estrutural de afloramentos ao longo da rodovia BR-262, que liga Belo Horizonte à Vitória, entre os municípios de Marechal Floriano e Ibatiba (ES). Esse perfil apresenta extensão aproximada de $100 \mathrm{~km}$ e direção ESE-WNW, ou seja, ortogonal à estruturação regional neste trecho do cinturão.

A análise geométrica baseou-se na descrição das feições planares e lineares e hierarquização das estruturas tectônicas segundo procedimento clássico descrito em Hobbs et al. (1976). Durante a análise, foram separadas as estruturas metamórficas das magmáticas. Paralelamente, foram analisadas as estruturas segundo os planos $\mathrm{XZ}$ do elipsóide de deformação finita, visando definir o sentido de rotação do fluxo a partir da interpretação do giro das estruturas assimétricas (ver sínteses em Simpson \& Schmid 1983, Lister \& Williams 1983, Hanmer \& Passchier 1990, Passchier \& Trouw 1996, entre outros).

SEÇÃO MARECHAL FLORIANO-IBATIBA Ao longo da seção estudada, foram reconhecidas, de leste para oeste, as seguintes unidades: gnaisses aluminosos da região de Marechal Floriano, granitos de Vitor Hugo e Aracê, biotita gnaisses, Batólito de Muniz Freire e milonitos das zonas de cisalhamentos de Guaçuí e Ibatiba (Fig. 2).

Os gnaisses aluminosos da região de Mal. Floriano, atribuídos ao Complexo Paraíba do Sul, possuem trama planar, com estrutura gnáissica bem desenvolvida, caracterizada por bandas centimétricas a decimétricas, contendo níveis de minerais félsicos (quartzo e felspatos) intercalados com níveis de minerais máficos ricos em biotita. Ocorrem, ainda, granada e cordierita associadas principalmente aos níveis félsicos e, sillimanita, aos níveis máficos.

O Granito de Vitor Hugo trata-se de um corpo estratóide, em contato concordante com os gnais-

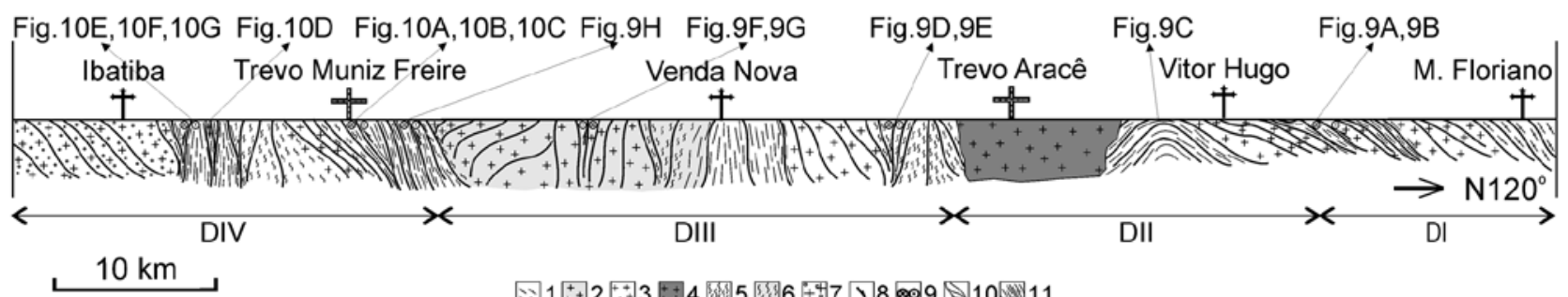

Figura 2 - Perfil geológico entre os municipios de Marechal Floriano e Ibatiba (ES). 1- Complexo Paraíba do Sul; 2- Batólito Muniz Freire; 3- Granito de Vitor Hugo; 4- Granito Aracê; 5- Biotita gnaisse; 6- Batólito Muniz Freire - porções deformadas; 7 Batólito Muniz Freire - granulação fina; 8- Sentido de movimentação tectônica; 9- Zonas de cisalhamento direcionais destrais; 10- Foliação metamórfica e magmática; 11- Foliação milonítica. Numeração das estruturas analisadas nas figuras 9 e 10. 
ses aluminosos de Mal. Floriano, que afloram a leste, e biotita gnaisses miloníticos, que afloram a oeste do mesmo. Corpo semelhante ocorre a oeste do trevo para Afonso Claúdio e a leste de Venda Nova do Imigrante. São rochas de cor cinza-clara a esbranquiçada, granulação média a grossa, com estrutura muitas vezes orientada, particularmente nas bordas do corpo, além de porções isótropas, com feições magmáticas preservadas. Este corpo foi descrito no Projeto de Levantamentos Geológicos Básicos do Brasil - PLGB da CPRM, folha Domingos Martins, escala 1:100.000, como Ortognaisse Tonalítico Tipo Jequetibá (Féboli 1993).

A unidade de biotita gnaisses situa-se próxima ao trevo de Afonso Claúdio e corresponde a uma faixa verticalizada que faz contato a leste com o Granito Aracê e a oeste com Granito de Vitor Hugo. Caracteriza-se por uma rocha de estrutura planar bem desenvolvida, por vezes bastante alterada, com bandas em geral decimétricas, contendo alternâncias de níveis félsicos (quartzo-feldspá- ticos) e máficos ricos em biotita e anfibólio. Nestas rochas observa-se ainda intercalações anfibolíticas e porções localizadas com estrutura predominantemente milonítica.

O Granito de Aracê corresponde a um corpo discordante e apresenta contatos verticais a oeste e a leste com biotita gnaisses miloníticos. Destaca-se no relevo por formar elevações do tipo "Pão de Açucar". Trata-se de uma rocha de cor cinza-clara a esbranquiçada, com estrutura isotrópica, de granulação fina a média, de composição sieno a monzogranítica, com porções granodioríticas a tonalíticas e injeções pegmatíticas nas suas bordas.

O Batólito Muniz Freire possui estrutura que varia de maciça a orientada, com foliação magmática incipiente em zonas de baixa deformação (Fig. 3A) até gnáissica nas zonas de máxima deformação, particularmente nas bordas, onde a orientação é definida pela biotita, quartzo e feldspatos estirados (Fig. 3B). Nestes locais, ocorre o desenvolvimento de um bandamento milimétrico, irregular e pouco definido, caracteriza-
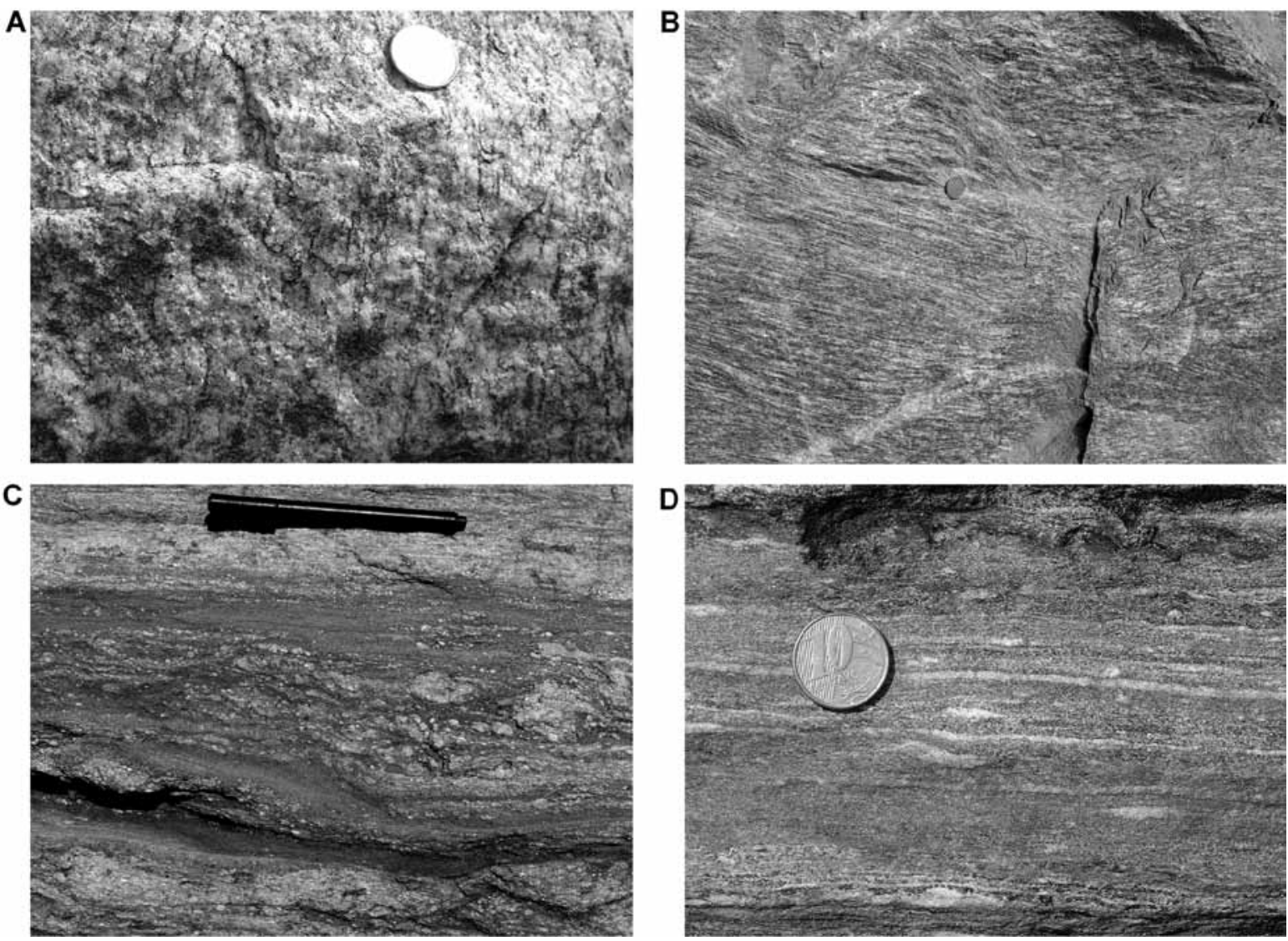

Figura 3 - Fotografias de estruturas planares. A- Granito deformado do Batólito Muniz Freire exibindo foliação magmática realçada por trilhas de biotita irregulares; $B$ - Borda deformada do Batólito Muniz Freire onde se observa uma foliação metamórfica com geometria planar caracterizada bor um bandamento milimétrico a centimétrico que é seccionado por planos $C$ 'de folações (porção superior da imagem) e diques leucograníticos de espessura centimétrica (porção inferior). C-Biotita gnaisse em uma faixa marginal à Zona de Cisalhamento Guaçuí com foliação formada por faixas milimétricas a centimétricas félsicas (quartzo e feldspato) e máficas (biotita) e porfiroclastos de feldspato com geometria sigmoidal; D- Milonito da Zona de Cisalhamento Ibatiba com foliação anastomosada, concentração de porfiroclastos estirados de feldspato (porção central) e faixas centimétricas a decimétricas de leucogranito milonítico (partes superior e inferior da imagem). 
do pela intercalação de níveis félsicos de composição quartzo-feldspática e níveis máficos ricos em biotita. As porções mais homogêneas possuem textura equigranular hipidiomórfica média $(2-5 \mathrm{~mm})$ a grossa (> $5 \mathrm{~mm}$ ), definida pela presença de cristais subédricos de K-feldspato, plagioclásio, biotita e quartzo de forma amebóide. No extremo oeste da seção, contudo, há predomínio de uma textura equigranular fina. Neste conjunto de rochas predomina uma composição monzogranítica e, subordinamente, granodiorítica.

São comuns ao longo da seção zonas de cisalhamento dúcteis, de espessura da ordem de centenas de metros a quilométrica (até $5 \mathrm{~km}$ ), destacando-se, dentre elas, na porção oeste, as zonas de alto ângulo de Guaçuí e Ibatiba. Na parte leste da seção ocorre uma zona de cisalhamento de mergulho intermediário, que é cortada a oeste pelo Granito Aracê. Ocorrem, nessas zonas, desde biotita gnaisses finos miloníticos (Fig. 3C) até milonitos (Fig. 3D), além de quartzo-milonitos recristalizados. São comuns ainda granitos foliados, particularmente nas zonas de cisalhamento de alto ângulo.

GEOMETRIA A seção levantada compreende uma associação de rochas intrusivas, controladas por zonas de cisalhamento em geral de alto ângulo e de maciços discordantes com forma aproximadamente circular, sem deformação aparente, que podem ser relacionados a uma fase tardia do magmatismo granítico.

A foliação, em geral, apresenta mergulhos com sentidos opostos, dominantemente de médio a alto ângulo, o que caracteriza estruturas em leque, principalmente no setor oeste da seção. No setor leste, contudo, observamse rochas miloníticas caracterizadas por uma foliação de baixo ângulo que são afetadas por dobras abertas. A lineação mineral e de estiramento apresenta caráter predominantemente oblíquo a direcional em relação à foliação.
A seguir, os dados estruturais da seção levantada são agrupados e discutidos segundo os procedimentos descritos em Turner e Weiss (1963), que consistem basicamente na definição de domínios estruturais homogêneos quanto à orientação de um determinado elemento estrutural (planar ou linear), descritos a seguir de leste para oeste (ver Fig. 2).

Domínio Estrutural I Localizado no setor leste do perfil, próximo ao município de Marechal Floriano, este domínio compreende uma associação de gnaisses aluminosos, além de corpos intrusivos afetados por zonas de cisalhamento.

No extremo leste da seção, nos arredores de Marechal Floriano, a foliação consiste em planos centimétricos definidos pela orientação de biotita, sillimanita e moscovita, paralelos a faixas centimétricas a decimétricas de composição félsica, compostos por quartzo, feldspato, granada (até $25 \%$ em volume da rocha) e cordierita.

Esses gnaisses aluminosos apresentam contato oeste com tonalitos e granodioritos, que se intercalam às zonas de cisalhamento dúcteis (espessura métrica a decamétrica), associadas com quartzo milonitos, com mergulhos moderados para ESE. Estes últimos possuem textura equigranular média a grossa, exibindo por vezes estrutura gnáissica. São rochas que se destacam no relevo, formando elevações tipo "Pão de Açúcar" que, uma vez alteradas, exibem saprolito de cor amarelada a marrom, rico em quartzo.

Apesar desta variação litológica, nota-se um paralelismo da estrutura planar, que apresenta direção predominante NNE e mergulho intermediário para ESE, com concentrações secundárias nas direções N e NNW e mergulhos intermediários a baixos para E e ENE (Fig. 4A). A lineação é formada pelo alinhamento de agrega-
A

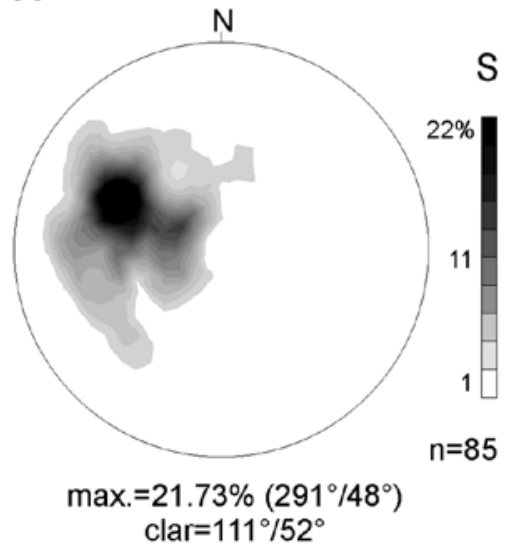

B

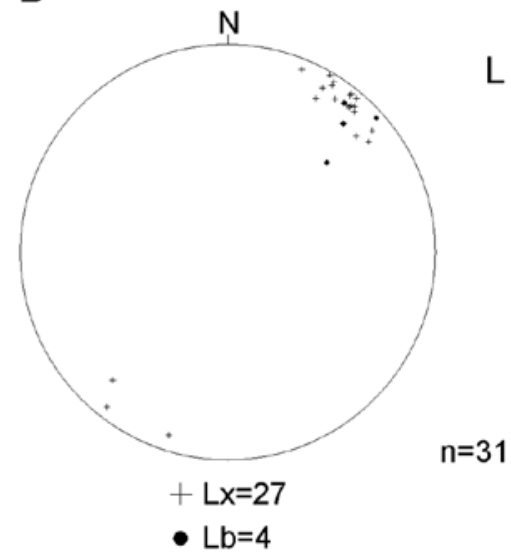

Figura 4 - Dados estruturais do Domínio Estrutural I. A- Pólos de foliação (S); BEstruturas lineares (L): Lx-lineação mineral e de estiramento, Lb-eixo de dobra. Projeção estereográfica em diagrama de igual área de Schmidt-Lambert, hemisfério inferior. Número de dados (n) indicado. 
dos de quartzo e feldspato, eventualmente com biotita nas zonas de cisalhamento, e se dispõe paralela a uma outra lineação mineral constituída de biotita e sillimanita nos gnaisses aluminosos e também a eixos de dobras. Essas lineações apresentam orientação predominantemente NE e caimento de baixo ângulo, direcional a levemente oblíqua em relação à foliação (Fig. 4B).

Domínio Estrutural II Este domínio contém quartzo milonitos associados com rochas básicas, em geral dobrados, que afloram próximo à cidade de Vitor Hugo. As rochas básicas ocorrem intercaladas na forma lentes, de espessura centimétrica a métrica, controladas por zonas de cisalhamento.

O setor ocidental do domínio é caracterizado por um maciço granítico (Maciço Aracê). Trata-se de um corpo discordante, de estrutura maciça, leuco a hololeucocrático, com predomínio de textura equigranular média. Nesse domínio, destacam-se no relevo elevações tipo "Pão de Açúcar", a exemplo da Pedra Azul, um atrativo turístico e símbolo do estado do Espírito Santo. Diques e apófises graníticas são comuns nas imediações do corpo.

Os dados estruturais do domínio referem-se a granitos deformados associados a zonas de cisalhamento. A foliação encontra-se afetada por dobras abertas e por estruturas S-C' de dimensões métricas. Em projeção estereográfica, nota-se uma concentração principal da foliação com direção NNE e mergulho baixo a intermediário para WNW. Nota-se, ainda, duas concentrações secundárias: uma com direção similar e mergulho idêntico, porém para ESE, e outra com direção NW e mergulho moderado para SW (Fig. 5A). Essa disposição dos dados é relacionada ao padrão de dobramento desse domínio. O diagrama sugere ainda uma guirlanda de uma dobra assimétrica com eixo de caimento suave para NNE.
A lineação é formada principalmente pelo estiramento de grãos de quartzo, por vezes associada também a anfibólio e biotita, particularmente nos trechos onde predominam rochas de composição básica. Apresenta concentração dominante no setor SSW do diagrama e caimento de baixo ângulo, que são paralelos aos eixos de dobras, bem como concentrações secundárias nos setores SSE e NE, com caimento sempre de baixo ângulo (Fig. 5B).

Domínio Estrutural III Este trecho corresponde ao setor centro-ocidental da seção, próximo ao município de Venda Nova do Imigrante. Caracteriza-se, a leste, por biotita gnaisse com estrutura planar bem desenvolvida em contato com biotita granito de coloração cinzaescuro, equigranular fino a médio. Este granito forma um corpo intrusivo aflorante na serra situada a leste de Venda Nova do Imigrante.

Milonitos profundamente alterados ocorrem nas imediações de Venda Nova do Imigrante, que são substituídos a oeste da referida cidade por granitos e granodioritos que constituem o Batólito Muniz Freire (Figs. 1 e 2). Trata-se de um corpo alongado, sendo comum foliação magmática de alto ângulo no seu interior e foliação no estado sólido, particularmente nas bordas (ver Figs. 3A e 3B), o que levou alguns pesquisadores em trabalhos anteriores a interpretá-lo como ortognaisse (Féboli 1993).

O domínio apresenta estrutura geral NNE. Notase, no entanto, um comportamento mais homogêno da foliação metamórfica, onde se destacam mergulhos altos para WNW e ESE (Fig. 6A). Já nas rochas graníticas, o comportamento dos dados da foliação é bastante heterogêneo: há orientações concordantes com a foliação metamórfica (mergulhos fortes para WNW e ESE) e discordantes, particularmente com mergulhos mais suaves e com dispersão na parte central do diagrama (Fig. 6B). A variação de direção e mergulho das estruturas pode ser
A

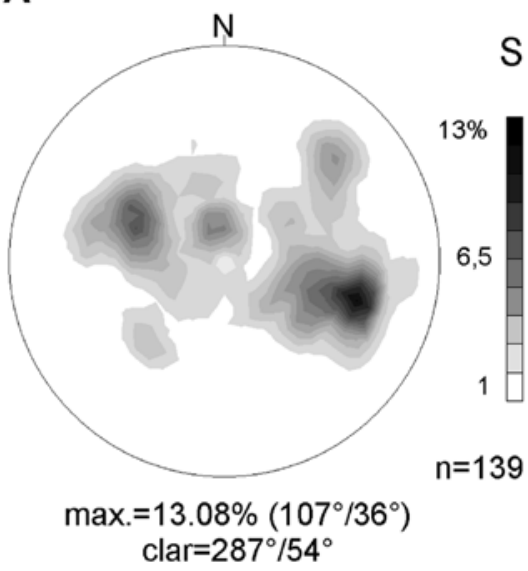

B

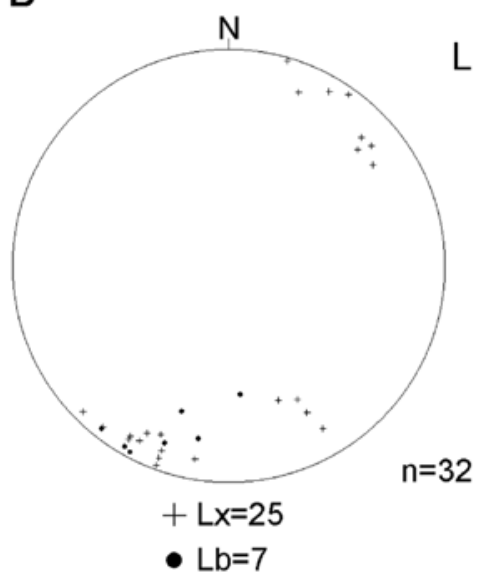

Figura 5 - Dados estruturais do Domínio Estrutural II. A-Pólos de foliação (S); $B$ - Estruturas lineares (L): Lx - lineação mineral e de estiramento, $L b$ - eixo de dobra. Projeção estereográfica em diagrama de igual área de Schmidt Lambert, hemisfério inferior. Número de dados (n) indicado. 
A

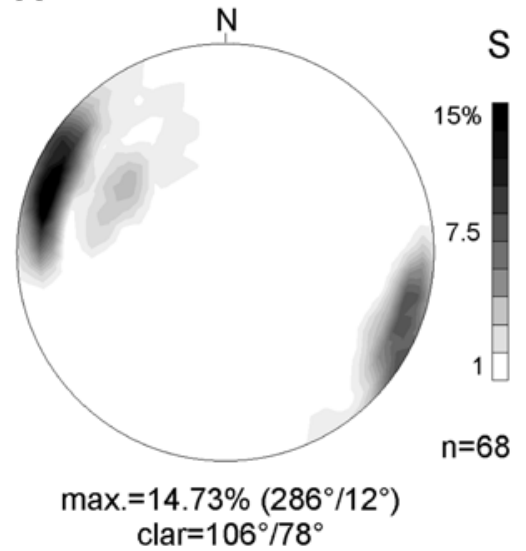

B

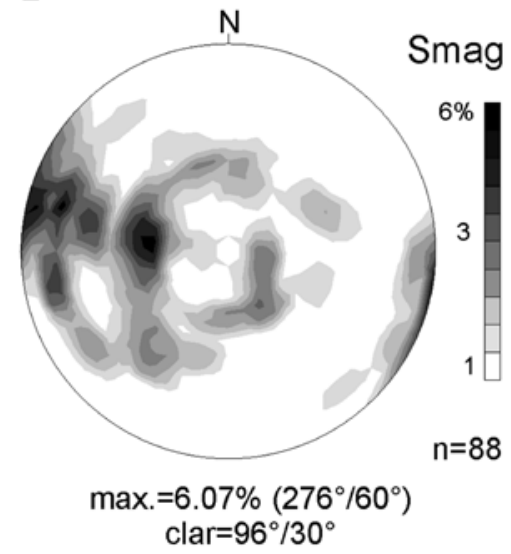

C

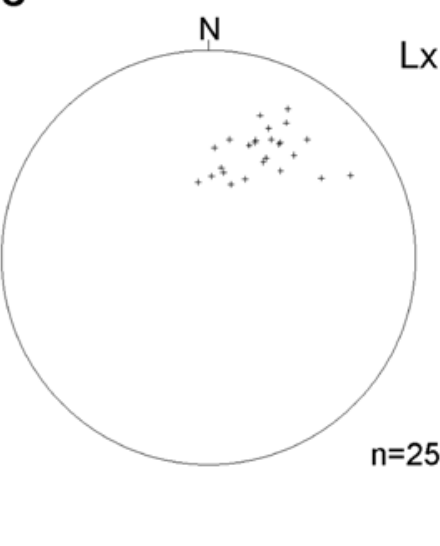

Figura 6 - Dados estruturais do Domínio Estrutural III. A-Pólos de foliação (S); B-Pólos de foliação magmática (Smag); C-Estruturas lineares (L): Lx-lineação mineral e de estiramento, Lb - eixo de dobra. Projeção estereográfica em diagrama de igual área de Schmidt Lambert, hemisfério inferior.

explicada pelo seu padrão anastomosado e pela presença de foliações com geometria em leque (estruturas em flor).

A lineação de estiramento caracteriza-se por agregados de quartzo, feldspato e biotita e é reconhecida principalmente em zonas deformadas de alto ângulo. Apresenta orientação principal NNE e caimento intermediário a baixo (Fig. 6C). A geometria da lineação é compatível com um padrão direcional a oblíquo em relação à foliação.

Domínio Estrutural IV O domínio IV, localizado no trecho oeste do perfil, possui foliação de médio a alto ângulo e contém as zonas de cisalhamento mais importantes da região. São faixas de espessura quilométrica, destacando-se a de Guaçuí, com cerca de $10 \mathrm{~km}$, e a de Ibatiba, com aproximadamente $4 \mathrm{~km}$ de espessura (Fig. 2). Nesses locais desenvolve-se uma trama planolinear, milonítica, com pares S-C e S-C' de foliações, porfiroclastos de feldspato assimétricos (ver Figs. 3C e D), entre outras estruturas associadas a uma deformação predominantemente por cisalhamento simples.

Rochas intrusivas, deformadas ou não, encontram-se associadas com estas zonas de cisalhamento, particularmente nos seus limites. Em geral, ocorrem como corpos concordantes que mostram um importante controle estrutural, com porções gnaissificadas e contatos gradacionais.

A foliação metamófica e milonítica nas zonas de cisalhamento e nos gnaisses apresenta direção NNE e mergulhos intermediários a altos para ESE e, secundariamente, altos para WNW (Fig. 7A). Já a foliação magmática apresenta mergulhos menos acentuados para ENE e, subordinamente, altos para SE e NW (Fig. 7A). Neste domínio nota-se também um paralelismo das lineações minerais e de estiramento com os eixos de dobras (Fig. 7B), as quais apresentam caimentos baixo a intermediário para NNE. Apesar de um número mais restrito de dados, verifica-se que a lineação magmática apresenta caimentos baixos para E e NE (Fig.
7B), o que mostra uma maior amplitude de variação no estereograma em relação às demais estruturas lineares.

ANÁLISE CINEMÁTICA Apesar da variação do padrão geométrico das estruturas na seção investigada, algumas características em comum podem ser destacadas: a foliação milonítica e gnáissica apresenta direção geral NNE e mergulho estatístico entre $45^{\circ}$ e $75^{\circ}$ para ESE e, secundariamente, mergulhos mais baixos para WNW (Fig. 8A). Já a foliação magmática mostra maior dispersão no estereograma e apresenta concentração principal com direção NNW e mergulho intermediário para ENE, e concentrações secundárias com direções ENE a NNE e mergulhos altos para WNW a NNW e subsidiariamente para SSE a ESE (Fig. 8B).

A lineação, por sua vez, apresenta orientações semelhantes em todos os domínios analisados, sugerindo assim um desenvolvimento independente do valor de mergulho da foliação. Observa-se uma concentração principal com caimentos dominantemente baixos para NNE e, secundariamente, para SSW, mostrando uma relação oblíqua a direcional com a foliação (Fig. 8C). Os eixos de dobras mostram-se subparalelos às lineações (Fig. 8D), sugerindo participação predominante de mecanismos de deformação por cisalhamento simples durante sua geração.

A seguir, são descritas estruturas assimétricas que auxiliaram na análise cinemática ao longo da seção (Figs. 9 e 10).

O desenvolvimento de quartzo milonitos com trama plano-linear está condicionado às zonas de máxima deformação, como em afloramentos localizados a leste de Vitor Hugo (ver Fig. 2), onde a estrutura caracteriza-se por pares S-C de foliação, em escala métrica, com ângulo elevado (entre 40 a $80^{\circ}$ ) entre os planos $\mathrm{S}$ e C, geometria compatível com movimentação transpressiva de topo para SW (Fig. 9A). A descrição de seções de possíveis dobras em bainha no mesmo local, observadas na seção YZ do 
A

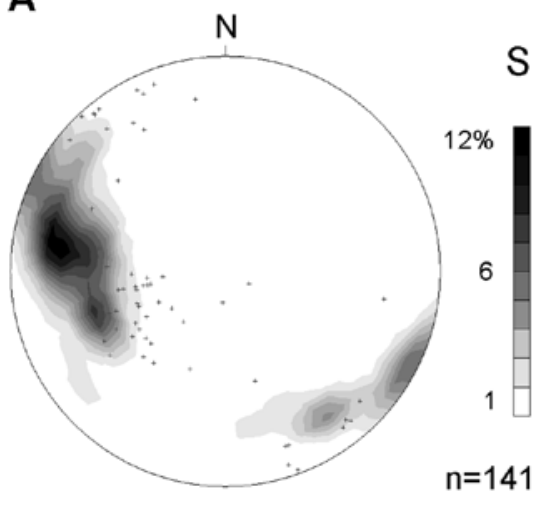

$\max .=11.92 \%\left(278^{\circ} / 24^{\circ}\right)$

clar $=98^{\circ} / 66^{\circ}$

+ Smag $=69$
B

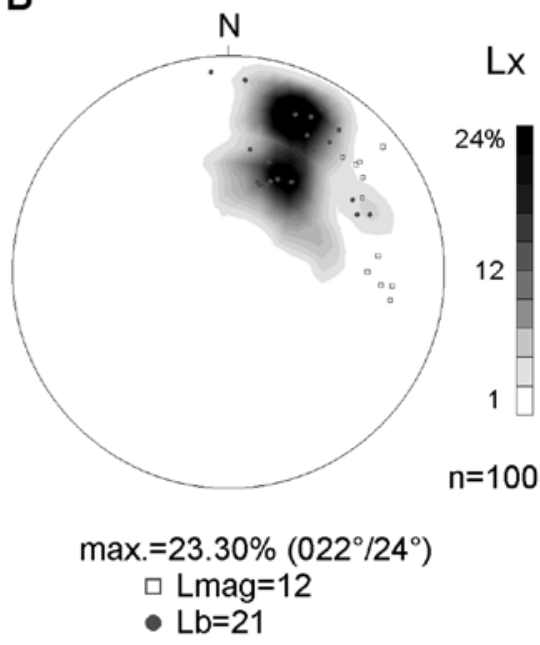

Figura 7 - Dados estruturais do Domínio Estrutural IV. A- Pólos de foliação (S) e foliação magmática (Smag); B-Estruturas lineares (L): Lx-lineação mineral e de estiramento, Lmag - lineação mineral magmática e Lb - eixo de dobra. Projeção estereográfica em diagrama de igual área de Schmidt Lambert, hemisfério inferior. Número de dados (n) indicado.

A

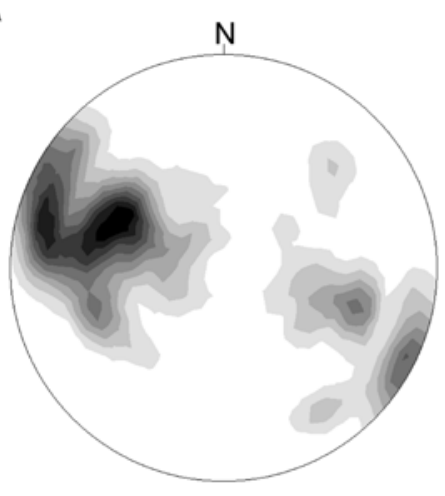

$\max .=6.95 \%\left(300^{\circ} / 48^{\circ}\right)$ clar $=120^{\circ} / 52^{\circ}$

C

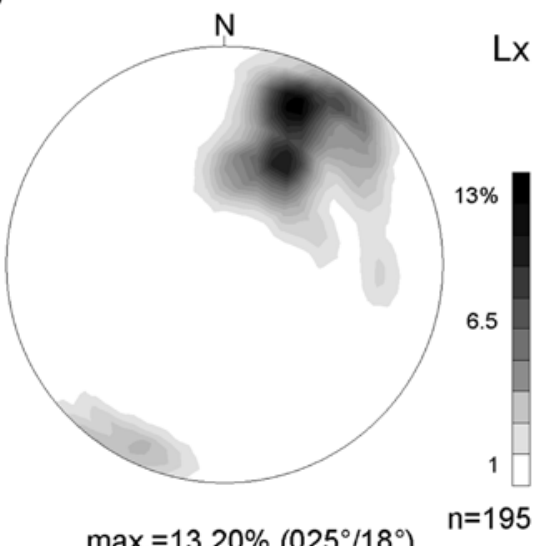

S

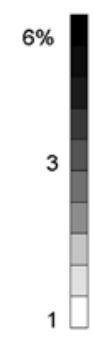

$n=434$

Lx

$\mathrm{n}=195$
B

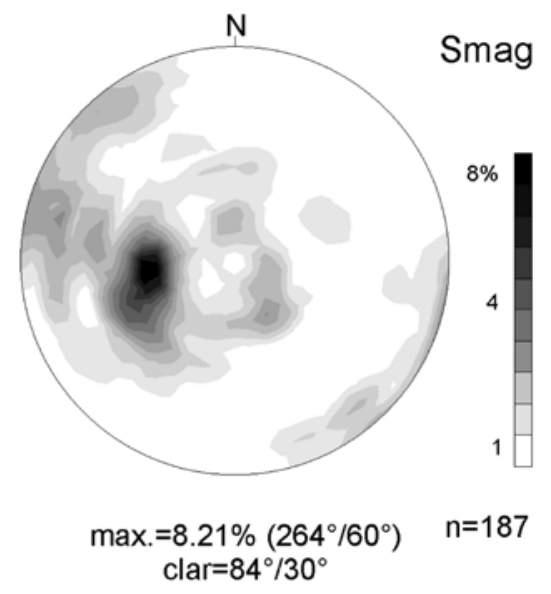

D

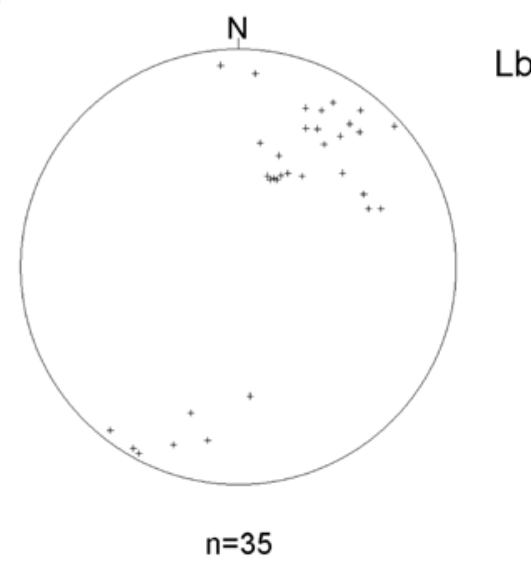

Figura 8 - Dados estruturais de toda a seção. A- Pólos de foliação (S); B-Pólos da Foliação magmática (Smag); C-Lineação mineral e de estiramento (Lx) e $D$ - Eixo de dobras (Lb). Projeção estereográfica em diagrama de igual área de Schmidt-Lambert, hemisfério inferior. Número de dados (n) indicado. 


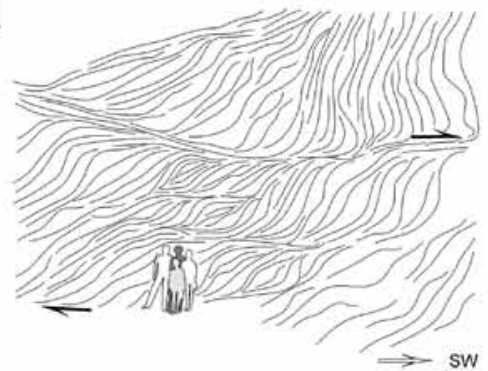

C

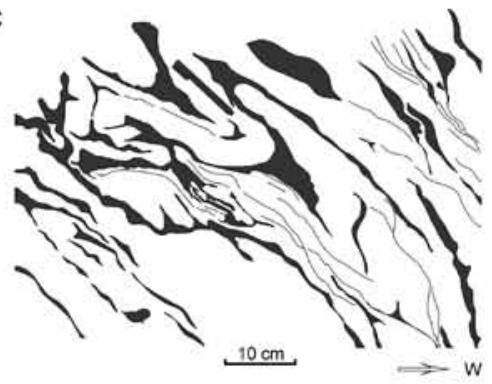

E

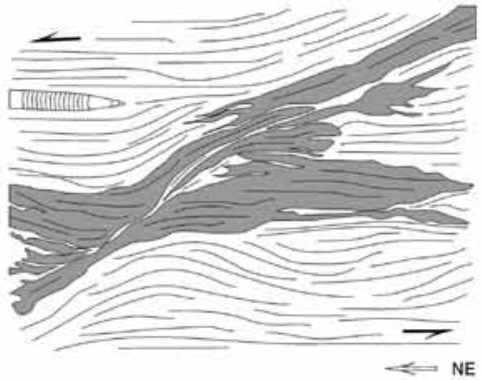

G

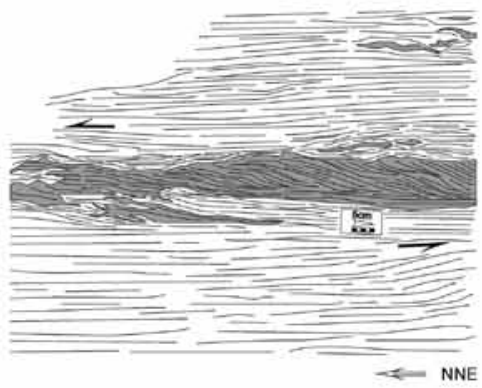

B



D

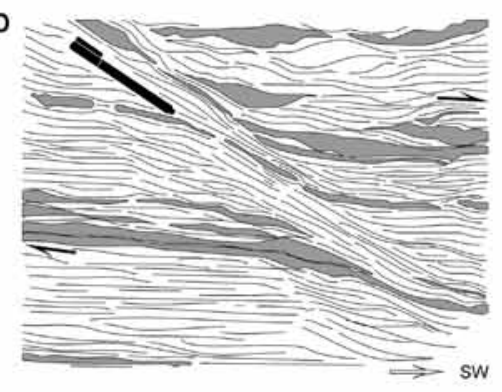

F

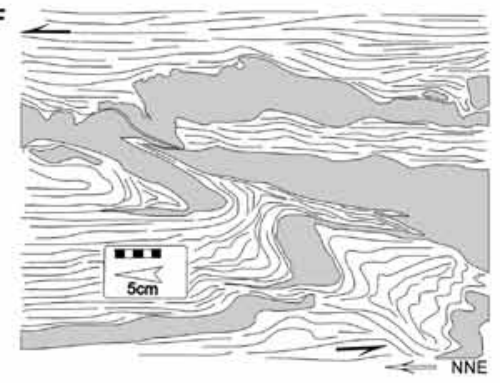

H

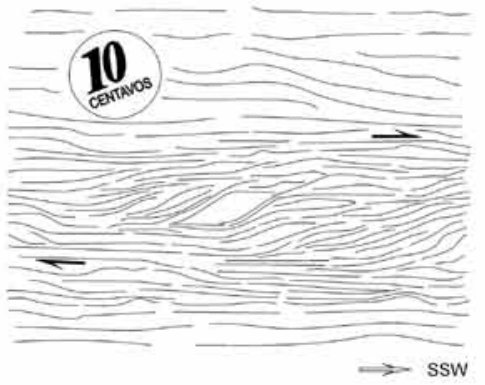

Figura 9 - Estruturas obtidas a partir da restituição de fotografias de afloramentos, descritas em cortes XZ do elipsóide de deformação finita (com exceção das figuras $B$ e $C$ ) com direções indicadas. A-Pares de foliações $S$ - $C$ de escala métrica, em afloramento a leste de Vitor Hugo, indicando movimentação relativa destral associada a um fluxo transpressivo para SW. Crianças com 1,5m de altura; B- No mesmo local, estrutura "em olho" interpretada como seção de dobra em bainha no corte YZ do elipsóide de deformação finita; $C$ - Seção de dobras fechadas com charneira espessada em quartzito. Estrutura realçada por níveis de composição básica (cinza). Estrutura observada em zona de cisalhamento de ângulo intermediário a oeste de Vitor Hugo; D-Lentes centimétricas de composição leucogranítica (cinza), paralelas a pares de foliações com geometria $S-C$ ', indicando movimentação destral. Biotita gnaisse com estrutura de alto ângulo, localizado a oeste do trevo de Aracê. Caneta com $14 \mathrm{~cm} ; \mathrm{E}-\mathrm{No}$ mesmo local, estrutura semelhante, porém com cinemática oposta. Ponta da lapiseira com $5 \mathrm{~cm}$; F- Veios de quartzo com geometria sigmoidal (cinza) compatível com movimentação sinistral. Porção deformada do Batólito Muniz Freire a oeste de Venda Nova com escala indicada; G- No mesmo local, a cinemática sinistral é evidenciada por pares $S-C$ de foliações e realçada pela foliação interna de um veio centimétrico de composição leucogranítica (cinza) e, $H$-Pares de foliações $S$-C observados em corte intemperizado da Zona de Cisalhamento Guaçuí, próximo ao trevo de Muniz Freire. Moeda com $3 \mathrm{~cm}$ de diâmetro. 
A

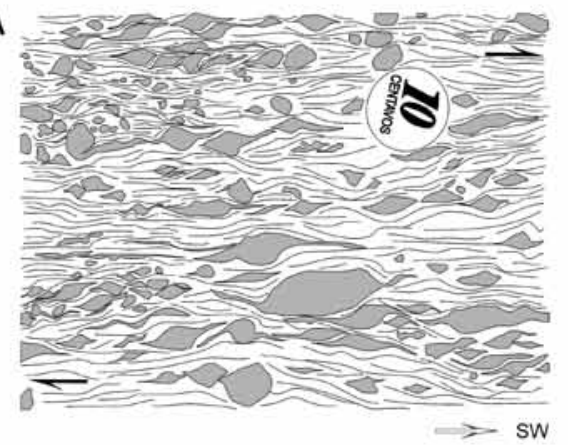

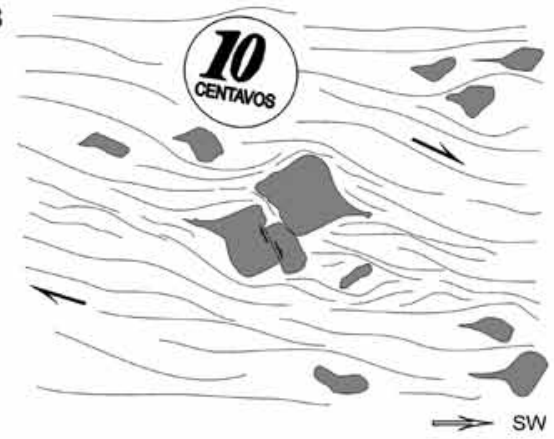

C

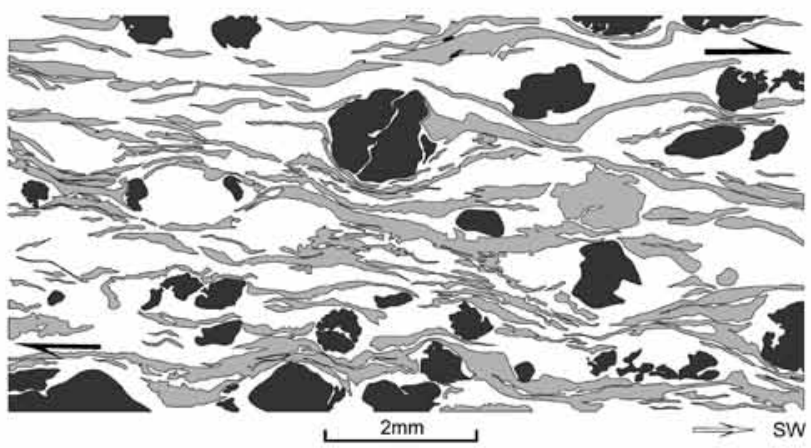

D

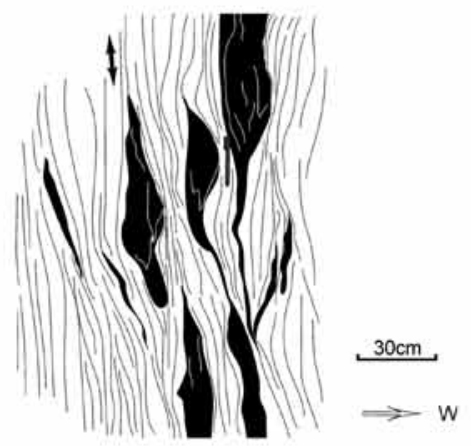

$\mathbf{F}$

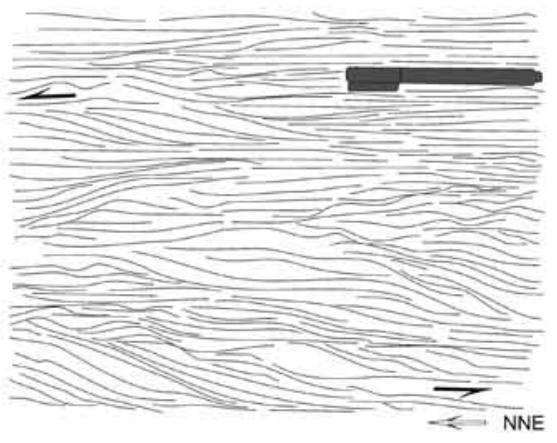

E

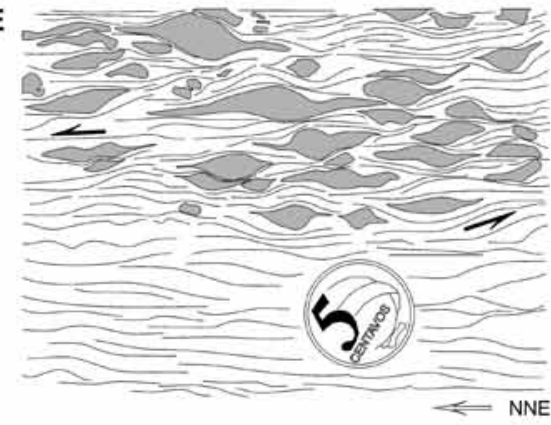

G

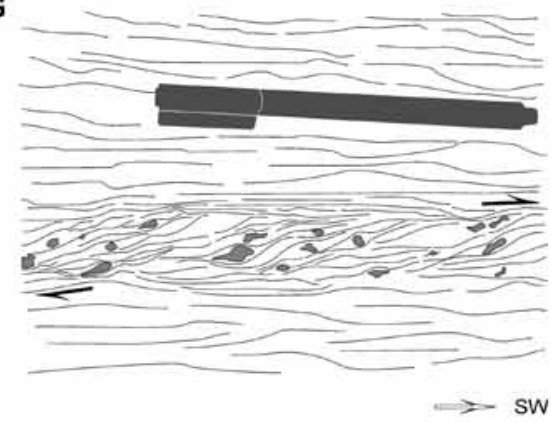

Figura 10 - Estruturas obtidas a partir da restituição de fotografias de afloramentos, descritas em cortes XZ do elipsóide de deformação finita com direções indicadas. A- Porfiroclastos de feldspato (cinza) centimétricos com geometria sigmoidal e segmentados por pares $S$-C' de foliações, compativel com movimentação lateral direita, associada a uma tectônica transpressiva para SSW na Zona de Cisalhamento Guaçuí. Moeda com $3 \mathrm{~cm}$ de diâmetro; B- No mesmo local, esta relação é sugerida por porfiroclasto de feldspato (cinza) com movimentação sintética ao longo de fratura; $C$-Seção delgada, ainda no mesmo afloramento, com porfiroclastos de feldspato (cinza escuro) contornados por ribbons de quartzo (cinza), indicando que a movimentação destral é uma feição penetrativa em diversas escalas; D- Seção vertical na Zona de Cisalhamento Ibatiba com enclaves anfibolíticos (preto) estirados verticalmente; E- Porfiroclastos de feldspato (cinza) com geometria sigmoidal contornados por bandas de cisalhamento centimétricas que conferem à rocha uma geometria S-C', compativel com movimentação sinistral. Moeda com 2,5 cm de diâmetro; $F$ - No mesmo afloramento são observados pares $S-C$ de foliações com cinemática compativel. $C a-$ neta com $14 \mathrm{~cm}$ e G-Pares $S$-C de foliações associados com porfiroclastos estirados, ainda no mesmo afloramento, indicando cinemática oposta em relação às duas figuras anteriores. 
elipsóide de deformação finita, pode também ser relacionada ao regime transpressivo (Fig. 9B), assim como dobras fechadas com charneira espessada descritas em outra zona de cisalhamento próxima (Fig. 9C).

A oeste do trevo de Aracê aflora um biotita gnaisse com estrutura de alto ângulo, contendo uma lineação de estiramento mineral subhorizontal, onde observam-se estuturas de pares S-C' de foliações, cuja geometria é compatível com cinemática destral (Fig. 9D) e sinistral (Fig. 9E).

O Batólito Muniz Freire apresenta, particularmente nas bordas, porções deformadas, caracterizadas por um bandamento centimétrico, que confere à rocha uma estrutura gnáissica. A oeste do trevo de Muniz Freire predomina uma cinemática sinistral, evidenciada por veios de quartzo com geometria sigmoidal (Fig. 9F) e pares S-C de foliações (Fig. 9G).

Na zona de cisalhamento de Guaçuí, imediatamente a oeste do trevo de Muniz Freire, os indicadores cinemáticos (porfiroclastos assimétricos de feldspatos, pares S-C' de foliações e fraturas sintéticas associadas) são consistentemente destrais e associam-se provavelmente a uma deformação transpressiva com fluxo tectônico para SSW. (Figs. 9H, 10A, 10B, 10C).

$\mathrm{Na}$ zona de cisalhamento de Ibatiba, situada a leste da cidade homônima, observam-se enclaves básicos com eixo maior orientado verticalmente (Fig. 10D). Nessa zona, as estruturas assimétricas sugerem cinemática predominantemente sinistral, indicada por porfiroclastos de feldspato sigmoidais (Fig. 10E) ou pares S-C de foliações (Fig. 10F), apesar da presença de pares S-C de foliações coerentes com movimentação oposta (Fig. 10G).

DISCUSSÃO E CONCLUSÕES As estruturas descritas (pares S-C, S-C' de foliações, porfiroclastos assimétricos, veios leucograníticos rotacionados) no presente trabalho são compatíveis com movimentação principal direcional a oblíqua, compatível com um fluxo tectônico para SSW. Indicadores cinemáticos sinistrais foram registrados em regiões com foliação de alto ângulo de mergulho para WNW, enquanto indicadores destrais foram registrados em regiões com foliação com mergulho intermediário a alto para ESE. Em ambos os casos, não há diferença no comportamento da lineação mineral. Observamse também afloramentos que contêm indicadores cinemáticos destrais e sinistrais, sem apresentarem, no entanto, relação de superposição cinemática (Figs.
9D e 9E; Figs. 10E, 10F e 10G).

Nos quatro domínios estruturais analisados, a lineação (estiramento e mineral) mostra orientação independentemente da geometria da foliação, sugerindo um desenvolvimento solidário durante o fluxo tectônico dúctil, situação comum em terrenos metamórficos de alto grau.

Evidencia-se ainda nos diagramas o paralelismo entre os eixos de dobras e lineações, sugerindo que tais estruturas foram formadas durante a mesma fase de deformação com movimentação para SSW. Alternativamente, estas estruturas poderiam ter sido formadas oblíquamente a este fluxo e, posteriomente, rotacionadas para uma direção paralela à lineação. A presença de dobras em bainha sugere, pelo menos em parte, uma deformação em regime não-coaxial.

A presença de milonitos associados com gnaisses miloníticos com estruturas assimétricas (porfiroclastos rotacionados e sigmoidais, pares $\mathrm{S}-\mathrm{C}$ de foliações, boudins assimétricos) reflete o desenvolvimento de zonas de máxima deformação, prevalecendo nesses locais mecanismos de deformação associados ao cisalhamento simples. Estas zonas mais deformadas alternam-se com zonas que contêm rochas menos deformadas, em geral com estruturas simétricas, compatível com predomínio de deformação por cisalhamento puro. Este aparente contraste dos mecanismos de deformação pode ser atribuido à partição da deformação em diferentes escalas, situação comum em orógenos desenvolvidos em regime transpressivo.

Vários autores têm reconhecido a importância do regime transpressivo na exumação de orógenos, particularmente relacionada com a extrusão tectônica ou escape lateral (Dias \& Ribeiro 1994, Jones et al. 1997), processo reconhecido em cinturões deformados antigos e modernos, como nos Caledonides (Chauvet e Sérrane 1994, Lyberis e Mamby 1999), no mar Egeu (Avigad et al. 2001), nos Alpes (Mancktelow 1992), no Cáucaso e nos Himalaias (Inger 1998) e na Província Mantiqueira Central (Vauchez et al. 1992, Trompette et al. 1993, Vauchez et al. 1994, Hackspacher \& Godoy 1999, Dehler 2002).

Os dados estruturais discutidos neste trabalho apontam para um regime de deformação oblíquo a paralelo ao orógeno, com cinemática dominantemente destral. Este quadro cinemático é semelhante ao contexto textônico caracterizado em outros segmentos do cinturão, como na região do vale do Rio Doce, no Espírito Santo (Nalini Jr. 1997, Karniol \& Machado 2004), e no vale do Paraíba do Sul, no Rio de Janeiro (Dehler 2002, Dehler et al. 2006, Karniol et al. 2007).

\section{Referências}

Almeida F.F.M, Hasui Y., Carneiro C.D.R. 1975. Lineamento de Além-Paraíba. An. Acad. Bras. Ciênc., 47:575.

Avigad D. \& Ziv A. \& Garfunkel Z. 2001. Ductile and brittle shortening, extension-parallel folds and maintenance of crustal thickness in the central Aegean (Cyclades, Greece). Tectonics, 20:277-287.

Bird P. 1991. Lateral Extrusion of Lower Crust from Under
High Topography, in the Isostatic Limit. J. Geoph. Res., 96:10.275-10.286.

Campanha G.A.C. 1981. O lineamento Além Paraíba na área de Três Rios (RJ). Rev. Bras. Geoc., 11:159-171.

Chauvet A. \& Séranne M. 1994. Extension-parallel folding in the Scandinavian Caledonides: implications for lateorogenic processes. Tectonophysics, 238:31-54. 
Cordani U.G., Delhal J., Ledent D. 1973. Orogéneses superposées dans Ia précambrien du Brésil Sud-oriental (Etats de Rio de Janeiro et Minas Gerais). Rev. Bras. Geoc., 3:1-22.

Chrispim S.J. \& Tupinambá M.A. 1989. Observações sobre o caráter transpressivo da deformação entre as zonas de cisalhamento do Paraíba do Sul (RJ) e Guaçuí (ES). In: SBG, Simp. Geol. Sud., 1, Atas, p. 120-121.

Cunningham D., Alkmim F.F., Marshak S. 1998. A structural transect across mobile belt in the Brazilian Highlands (latitude $20^{\circ} \mathrm{S}$ ): the roots of a Precambrian transpressional orogen. Prec. Res., 92: 251-275.

Dayan H. \& Keller J.V.A. 1989. A zona de cisalhamento do Rio Paraíba do Sul nas vizinhanças de Três Rios (RJ): uma análise da deformação dada por algumas feições estruturais. Rev. Bras. Geoc., 19:494-506.

Dehler N.M. 2002. Extrusão tectônica oblíqua em regime transpressivo no Cinturão Paraibides, RJ. Tese de Doutoramento, Iinstituto de Geociências, Universidade de São Paulo, São Paulo, 170 p.

Dehler N.M., Machado R., Vasconcelos C.S. 2000. Tectônica extensional oblíqua no sul do estado de São Paulo. Rev. Bras. Geoc., 30:699-706.

Dehler N.M \& Machado R. 2002. Geometria e cinemática da aba sul da estrutura divergente do Rio Paraíba do Sul ao longo da seção Areal-Três Rios, Rio de Janeiro. Rev. Bras. Geoc., 32:481-490.

Dehler N.M, Machado R., Dehler H., McReath I., Nummer A. 2006. Kinematics and geometry of structures in the southern limb of the Paraíba do Sul divergent structural fan, SE Brazil: a true transtensional shear. An. Acad. Bras. Ciênc., 78:1-17.

Dehler N.M, Rômulo M., Fassbinder E. 2007. Shear structures in the Serra do Azeite shear zone,southeastern Brazil: Transtensional deformation during regional transpression in the central Mantiqueira province (Ribeira belt). J. South Am. Earth Sci., 23:176-192.

Dias R. \& Ribeiro A. 1994. Constriction in a transpressive regime: an example in the Iberian branch of the IberoArmorican arc. J. Struc. Geol., 16:1543-1554.

Ebert H. D. \& Hasui Y. 1998. Transpressional tectonics and strain partitioning during oblique colision between three plates in the precambrian of south-east Brazil. In: Holdsworth R.E. \& Strachan R.A., Dewey J.F. (eds.) Continental transpressional and transtensional tectonics. London, Spec. Publ. Geol. Soc., 135:231-252.

Egydio-Silva M. 1996. Zona de cisalhamento de alta temperatura - o lineamento de Além-Paraiba (RJ). Petrotrama de plagioclásio - Anisotropia sísmica - Reologia da litosfera continental. Tese de Livre-Docência, Instituto de Geociências, Universidade de São Paulo, 226 p.

Egydio-Silva M., Vauchez, A, Bascou, J., Hippertt, J. F. 2002. High temperature deformation in the neoproterozoic transpressional Ribeira Belt, southeast Brazil. Tectonophysics, 352:203-224.

Endo I. 1997. Regimes tectônicos do Arqueano e Proterozóico no interior da placa sanfranciscana: Quadrilátero Ferrifero e areas adjascentes, Minas Gerais. Tese de Doutoramento, Instituto de Geociências, Universidade de São Paulo, 243 p.
Féboli W.L. 1993. Mapa geológico da Folha Domingos Martins - SF24-V-A-III. Programa de Levantamentos Geológicos Básicos do Brasil, DNPM/CPRM, escala $1: 100000$.

Fontes C.Q., Ferrari P.G., Pereira A.D.C., Netto C., Pereira F.S., Lima, JR. L.O., Costa M.R.A., Baltazar O.F., Silva S.L., Vieira V.S., Ramalho R. 1978. Projeto Jequitinhonha, DNPM/CPRM, escala 1:250.000.

Hackpacher P. \& Godoy A.M. 1999. Vertical displacement during late-collisional escape tectonics (Brasiliano Orogeny) in the Ribeira Belt, São Paulo State, Brazil. J. Afric. Earth Sci., 29:25-32.

Hanmer S. \& Passchier C.W. 1991. Shear-sense indicators: a review. Geol. Surv. of Canada, Paper 90-17, 72 p.

Harland W.B. 1971. Tectonic transpression in Caledonian Spitsbergen. Geol. Mag., 108:27-42.

Harz E.H., Andresen A., Hodges K.V., Martin M.W. 2001. Syncontractional extension and exhumation of deep crustal rocks in the east Greenland Caledonides. Tectonics, 20:58-77.

Hasui Y., Carneiro C.D.R., Coimbra A.M. 1975. The Ribeira folded belt. Rev. Bras. Geoc., 5:257-266.

Hasui Y. \& Oliveira M.A.F. 1984. A Província Mantiqueira Setor Central. In: Almeida F.F.M., \& Hasui Y. (coord.). O Pré-Cambriano do Brasil. São Paulo, Edgard Blücher, $378 \mathrm{p}$.

Heilbron M., Pedrosa-Soares A.C., Campos Neto M., Silva L.C., Trouw R.A.J., Janasi V.A. 2004. Província Mantiqueira. In: Mantesso-Netto V., Bartorelli A., Carneiro C.D.R., Brito-Neves B.B. (eds.) Geologia do continente sulamericano - evolução da obra de Fernando Flávio Marques de Almeida. São Paulo, Beca, p. 203-234.

Hobbs B.E., Means B.W.D., Williams P.F. 1976. An outline of structural geology. New York, John-Wiley \& Sons, $570 \mathrm{p}$

Inger S. 1998. Timing of an extensional detachment during convergent orogeny: New $\mathrm{Rb} / \mathrm{Sr}$ geochronological data from the Zanskar shear zone, northwestern Himalaya. Geology, 26:223-226.

James A.I. \& Watkinson A.J. 1994. Initiation of folding and boudinage in wrench shear and transpression. J. Struc. Geol., 16:883-893.

Jarrard R.D. 1986. Terrane motion by strike-slip faulting of forearc slivers. Geology, 14:780-783.

Jones R.R., Holdsworth R.E., Bailey W. 1997. Lateral extrusion in transpression zones: the importance of boundary conditions. J. Struc. Geol., 19:1201-1217.

Karniol T.R. \& Machado R. 2004. Análise geométrica e cinemática de um segmento na região do baixo Rio Doce entre Aimorés (MG) e Colatina (ES). Rev. Bras. Geoc., 34:373-382.

Karniol T.R., Machado R., Vicente L.C. 2007. Tectônica extensional no cinturão Paraíba do Sul no noroeste do Rio de Janeiro: análise estrutural na seção Itaperuna (RJ) Muriaé (MG). Rev. Bras. Geoc, 37: 625-636.

Karniol T.R., Machado R., Dehler N.M. 2008. Transpressive dextral shear in the Italva-Itaperuna section, northern state of Rio de Janeiro. An. Acad. Bras. Ciênc., 80: 565577.

Lister G.S. \& Williams P.F. 1983. The partitioning of defor- 
mation in flowing rock masses. Tectonophysics, 92:1-33.

Lyberis N. \& Mamby G. 1999. Continental collision and lateral escape deformation in the lower and upper crust: An example from Caledonide Svalbard. Tectonics, 18:40-63.

Machado N., Valladares C.S., Heilbron M., Valeriano C.M. 1996. U/Pb geochronology of the central Ribeira belt: implications for the evolution of brasiliano orogeny. Prec. Res., 79:347-361.

Machado R. 1984. Evolução geológica, análise estrutural e metamórfica da região de Vassouras e Paracambi, porção ocidental do Estado do Rio de Janeiro. Tese de Doutoramento, Instituto de Geociências, Universidade de São Paulo, 196 p.

Machado R. \& Endo I. 1993 a. A megaestrutura em flor positiva do Vale do Rio Paraíba do Sul no Rio de Janeiro e suas implicações tectônicas regionais. In: SBG, Simp. Geol. Sudeste, 3, Atas, p. 208-213.

Machado R. \& Endo I. 1993 b. Cinturão de Cisalhamento Atlântico: um exemplo de tectônica transpressiva neoproterozóica. In: SBG, Simp. Nac. Est. Tect., 4, Atas, p. 189-191.

Mancktelow N.S. 1992. Neogene lateral extension during convergence in the Central Alps: Evidence from interrelated faulting and backfolding around the Simplonpass (Switzerland). Tectonophysics, 215:295-317.

Marshak S., Alkmim F., Whittington C., Pedrosa-Soares A.C. 2006. Extensional collapse in the Neoproterozoic Araçuaí orogen, eastern Brazil: a setting for reactivation of asymmetric crenulation cleavage. J. Struc. Geol., 28:129-147.

Nalini Jr. A. 1997. Caractérisation des suites magmatiques néoprotérozoïques de la région de Conselheiro Pena et Galiléia (Minas Gerais, Brésil): étude géochimique et structurales des suites Galiléia et Urucum et leur relation avec les pegmatites à élements rares associées. Tese de Doutoramento, École des Mines de Saint-Étienne e École des Mines de Paris, França, 237 p.

Noce C.M., Pedorsa-Soares A.C., Silva L.C., Armstrong R., Piuzuna D. 2007. Evolution of polycyclic basement complexes in the Araçuaí Orogen, base on U-Pb SHRIMP data: Implications for Brazil-Africa links in Paleoproterozoic time. Prec. Res., 159:60-78.

Passchier C.W. \& Trouw R.A.J. 1996. Microtectonics. Berlim, Springer-Verlag, $289 \mathrm{p}$.

Peres G.G., Alkmim F.F., Jordt-Evangelista H. 2004. The southern Araçuaí belt and the Dom Silvério Group: geologic architecture and tectonic significance. An. Acad. Bras. Ciênc., 76:771-790.

Ratschbacher L., Frisch W., Linzer H., Merle O. 1991. Lateral extrusion in the eastern Alps, part II: Structural Analysis. Tectonics, 10:257-271.

Reis A.P., Rocha R.S., Barbosa A.L.M., Lima E.C. Von S., Sad J.H., Alves M.R, Baltazar O.F. 1982. Geologia das folhas Varre-Sai, Eugenópolis, Itaperuna e Miracema,
RJ. In: SBG, Congr. Bras. Geol., 32, Anais, p. 86-93.

Robin P.Y.M. \& Cruden A.R. 1994. Strain and vorticity patterns in ideally ductile transpression zones. J. Struc. Geol., 16:447-466.

Sanderson D.J. \& Marchini W.R.D. 1984. Transpression. J. Struc. Geol., 6:449-458.

Seyferth M. \& Henk A. 2004. Syn-convergent exhumation and lateral extrusion in continental collision zones - insights from three-dimensional numerical models. Tectonophysics, 382:1-29.

Silva L.C., McNaughton N.J., Armstrong R., Hartmann L.A., Fletcher I. R. 2005. The neoproterozoic Mantiqueira Province and its African connections: a zircon-based $\mathrm{U}-\mathrm{Pb}$ geochronologic subdivision for the Brasiliano/ Pan-African systems of orogens. Prec. Res., 136:203240.

Signorelli N. 1993. Folha Afonso Cláudio - SF24-V-A-II. Programa de Levantamentos Geológicos Básicos do Brasil, DNPM/CPRM, escala 1:100000.

Simpson C. \& Schmid S.M. 1983. An evaluation of criteria to deduce the sense of movement in sheared rocks, Geol. Soc. Am. Bull., 94:1281-1288.

Söllner F., Lammerer B., Weber-Diffenback K. 1991. Die krustenentwiclkung nordlich von Rio de Janeiro/Brasilien. München, Münchner Geologische Hefte, v.4, 100 p.

Söllner F., Lammerer B., Wiedemann-Leonardos C., 2000: Dating the Ribeira Mobile Belt of Brazil. Zeits. Ang. Geol., SH1:245-255.

Teixeira W., Sabaté P., Barbosa J.S.F., Noce C.M., Carneiro M.A. 2000. Archean and Paleoproterozoic tectonic evolution of the São Francisco Craton. In: Cordani U.G., Milani E.J., Thomaz-Filho A., Campos D.A. (eds.) Tectonic Evolution of South America. Rio de Janeiro, p.101-138.

Tikoff B. \& Teyssier C. 1994. Strain modeling of displacement-field partitioning in transpressional orogens. Journal Structural Geology, 16:1575-1588.

Trompette R., Egydio-Silva M., Tommasi A., Vauchez A., Uhlein A. 1993. Amalgamação do Gondwana Ocidental no Panafricano-Brasiliano e o papel da geometria do Cráton do São Francisco na arquitetura da Faixa Ribeira. Rev. Bras. Geoc., 23:187-93.

Turner F.J. \& Weiss L.E. 1963. Structural Analysis of Metamorphic Tectonites. New York, McGraw Hill, 545 p.

Vauchez A., Tommasi A., Egydio-Silva M. 1994. Self indentation of a heterogeneous continental lithosphere. Geology, 22:967-970.

Vauchez A., Tommasi A., Silva M.E., Trompette R. 1992. Tectônica de escape na terminação de um craton: a Faixa Ribeira. In: SBG, Cong. Bras. Geol., 37, Boletim de Resumos Expandidos, p. 373-375.

Manuscrito ID 12683

Submetido em 24 de outubro de 2008 Aceito em 02 de fevereiro de 2010 